This article is licensed under the Creative Commons Attribution-NonCommercial-NoDerivatives 40 Intema-

\title{
Cardiac Contractility Modulation Attenuate Myocardial Fibrosis by Inhibiting TGF- $\beta 1 /$ Smad3 Signaling Pathway in a Rabbit Model of Chronic Heart Failure
}

\author{
Feifei Zhang ${ }^{\mathrm{a}}$ Yi Dang ${ }^{\mathrm{b}}$ Yingxiao Lib ${ }^{\mathrm{b}}$ Qingqing Hao ${ }^{\mathrm{b}}$ Rong $\mathrm{Li}^{\mathrm{a}}$ Xiaoyong Qia,b \\ aSchool of Graduate, Hebei Medical University, Shijiazhuang, bDepartment of Cardiology Center, Hebei \\ General Hospital, Shijiazhuang, China
}

\section{Key Words}

Cardiac contractility modulation $\bullet$ Heart failure $\bullet$ Myocardial fibrosis $\bullet$ TGF- $\beta 1 \cdot$ Smad3

\begin{abstract}
Backgroun/Aims: To explore the effect of cardiac contractility modulation (CCM) on myocardial fibrosis in heart failure and to investigate the underlying mechanism. Methods: Rabbits were randomly divided into sham group, HF group and CCM group. A rabbit model of chronic heart failure (CHF) was induced 12 weeks after aortic constriction by pressure unloading. Then cardiac contractility modulation was delivered to the myocardium lasting six hours per day for 4 weeks. Histology examination was carried out to evaluate the myocardial pathological changes. Protein levels of collagen I, collagen III, $\alpha$-SMA, MMP2, MMP9, TIMP1, TGF- $\beta 1$ and Smad3 were measured by western blot analysis. Results: Histology examination results showed that CCM therapy attenuated myocardial fibrosis and collagen deposition in rabbits with CHF. In addition, protein levels of collagen I, collagen III, $\alpha$-SMA, MMP2, MMP9, TIMP1, TGF- $\beta 1$ and Smad3 were down regulated. Conclusion: CCM therapy exerted protective effects against myocardial fibrosis potentially by inhibiting TGF- $\beta 1 / \mathrm{Smad} 3$ signaling pathway in $\mathrm{CHF}$ rabbits.
\end{abstract}

\section{Introduction}

Chronic heart failure (CHF) is the terminal stage of various structural and functional cardiac diseases, characterized by a progressive reduction in cardiac output. Despite tremendous efforts during the past decades, CHF remains one of the most common, costly 


\section{Cellular Physiology Cell Physiol Biochem 2016;39:294-302 \begin{tabular}{l|l} 
and Biochemistry Published online: June 27, 2016 & $\begin{array}{l}\text { D) } 2016 \text { The Author(s). Published by S. Karger AG, Basel } \\
\text { www.karger.com/cpb }\end{array}$ \\
\hline
\end{tabular} \\ Zhang et al.: Cardiac Contractility Modulation Attenuate Myocardial Fibrosis}

and deadly deceases. The pathological cardiac remodeling is characterized by myocardial hypertrophy, cell apoptosis, and myocardial interstitial fibrosis, and resulting structural changes contribute to the process of cardiac dysfunction [1]. Cardiac interstitial fibrosis, the excessive deposition of extracellular matrix (ECM), is one of the major contributing factors in the pathogenesis of heart failure [2]. The excessive deposition of ECM proteins leads to poor cardiac performance due to disorganized electrical signaling and the inability to contract [3, 4].

Cardiac contractility modulation (CCM) is the application of relatively high intensity, non-excitatory signals to the myocardium, during the absolute refractory period that has been shown to augment contraction strength of myocardium and improve exercise tolerance and quality of life [5-9]. The action of increase in contraction force appears to be mediated by reversing the molecular remodeling associated with heart failure and restore the expression of several calcium handling proteins [10-12]. It has also been reported that CCM has a favorable effect on cardiac remodeling by echocardiography and histological assessment and normalizes expressions of key cytoskeleton proteins and matrix metalloproteinase (MMPs) [13-15]. Our previous study has demonstrated that CCM could normalize the expression of SERCA2a/phospholamban and miR-133 in CHF rabbits, which contributes to the multiaspect cardioprotective action of CCM [16].

TGF- $\beta 1$ has been shown to play an important part in the pathogenesis of myocardial fibrosis which causes the deposition of ECM via the enhancement of ECM synthesis and reduction of ECM degradation [17-20]. Smad3 is the key mediator in the downstream of TGF- $\beta 1$ signaling pathway under various pathological conditions [21]. Emerging evidences showed miR-133 could improve the fibrosis process by regulating the expression levels of TGF- $\beta 1$ and CTGF $[22,23]$. We have previously demonstrated that CCM unregulated miR133 level, which benefited cardiac function [16]. In this study, we sought to investigate the potential relationship between CCM and TGF- $\beta 1 /$ Smad3 signaling pathway in a rabbit model of $\mathrm{CHF}$ and to explore the role of CCM in myocardial fibrosis.

\section{Materials and Methods}

\section{Ethics statement}

All of the procedures involving animals were in full compliance with the Guide for the Care and Use of Laboratory Animals published by the US National Institutes of Health. The design of this study was approved by the Institutional Animal Care Committee at Hebei Medical University.

Animals

Thirty healthy New Zealand white rabbits of both genders weighing 2.5 - $3.5 \mathrm{~kg}$ ( 6 months old) were purchased from the Experimental Animal Center of Hebei Medical University.

\section{Group setting}

The rabbits were randomly divided into the following three groups: sham operation group (sham group, $n=10$ ), heart failure group (HF group, $n=10$ ), and CCM + heart failure group (CCM group, $n=10$ ). In the sham group, rabbits only received thoracotomy; in the HF group, rabbits underwent thoracotomy and ascending aortic cerclage; in the CCM group, rabbits received thoracotomy, ascending aortic cerclage and 4-week CCM after heart failure.

\section{Model of CHF}

The rabbit model of CHF induced in the present study was previously described in detail [16]. Briefly, following the induction of anesthesia in rabbit via ear vein administration of $3 \%$ sodium pentobarbital at $1 \mathrm{ml} /$ $\mathrm{kg}$ body weight, the thoracic cavity was opened. The ascending aorta was dissected and the circumference of aorta was calculated and occluded to make a constriction to $60 \%$ of the original circumference. The electrode used to deliver CCM was sutured to left ventricular anterior wall and the other ends of the electrode were punctured subcutaneously to the neck for later use. After 12 weeks, symptoms of heart failure occurred 


\section{Cellular Physiology Cell Physiol Biochem 2016;39:294-302 \begin{tabular}{l|l} 
and Biochemistry Published online: June 27,2016 & $\begin{array}{l}\text { D) } 2016 \text { The Author(s). Published by S. Karger AG, Basel } \\
\text { www.karger.com/cpb }\end{array}$ \\
\hline
\end{tabular} \\ Zhang et al.: Cardiac Contractility Modulation Attenuate Myocardial Fibrosis}

in the rabbits, such as loss of appetite, reduction of activities and breathing acceleration. Left ventricular ejection fraction $\leq 40 \%$ meant that the heart failure model had been successfully established.

\section{CCM protocols}

EPS320 Cardiac Stimulator (BARD MicroPace, Inc, USA) was used to deliver CCM signals to the absolute refractory period of heart by sensed R-wave. As detailed previously, the signals consisted of a biphasic square-wave pulses with phase duration $=2 \mathrm{~ms}$, stimulus amplitude $=7 \mathrm{~V}$, and $30 \mathrm{~ms}$ delay after R-wave sensing [16]. CCM signals lasted 6 hours per day for consecutive 4 weeks.

\section{Histology and immunohistochemistry}

The heart from anesthetized rabbits was rapidly excised, and fixed in 4\% paraformaldehyde solution. The heart was sectioned transversely across myocardial papillary muscle, and then embedded with paraffin. Myocardial tissue sections $(5 \mu \mathrm{m})$ were cut from the paraffin blocks and stained with hematoxylin and eosin (H\&E) and Masson's trichrome for histopathological analysis of myocardial fibrosis. Digital microscope ( $\times 400$; BX-51; Olympus, Tokyo, Japan) was used to take pictures of ten random fields from each heart section. The collagen volume fraction (CVF) was calculated as the sum of the connective tissue areas divided by the sum of all connective tissue and muscle area. The expression of $\alpha$-SMA in the myocardium was immunolocalized with antibodies against $\alpha$-smooth muscle action ( $\alpha$-SMA; both 1:50 dilution, Bio-high, Shijiazhuang, China). A negative control was prepared by incubating the tissue with an anti-IgG (1:200 dilution, Bio-high, Shijiazhuang, China) antibody without primary antibody. Digital photographs were taken at $400 \times$ magnification for 10 random fields from each section, and percentages of positive signals were quantitative. Data were analyzed using Image-ProPlus5.1 (Media Cybernetics).

\section{Western blot analysis}

The total protein samples were extracted from heart tissues and quantified using the bicinchoninic acid (BCA) protein assay (Beyotime, Shanghai, China). Samples were separated with 10\% SDS-PAGE electrophoresis and transferred to polyvinylidene difluoride (PVDF) membranes. After blocked with $5 \%$ fat-free milk for $2 \mathrm{~h}$, the membrane was incubated overnight with primary antibody at $4^{\circ} \mathrm{C}$, with the antibodies of collagen I (1:400, Bioss, Beijing, China), collagen III (1:600, Bioss, Beijing, China), matrix metalloproteinase 2 (MMP2; 1:500, Bioss, Beijing, China), MMP9 (1:800, Bioss, Beijing, China), tissue inhibitor of metalloproteinase 1 (TIMP1; 1:600, Bioss, Beijing, China), $\alpha$-SMA (1:50, Bio-high, Shijiazhuang, China), Smad3 (1:600, Bioss, Beijing, China) and TGF- $\beta 1$ (1:500, Bioss, Beijing, China). $\beta$-actin (1:1500, Bioss, Beijing, China) was used as a control. The immunoreactive bands were visualized using the enhanced chemiluminescence kit (ECL Millipore Corp., Bedford, MA, USA). Developed films were scanned and ImageProPlus 5.1 was used for quantitative analysis.

\section{Statistical analysis}

All data were presented as mean \pm standard deviation and analyzed using the Statistical Package for Social Sciences (SPSS) for Windows version 17.0 software (SPSS Inc., Chicago, IL, USA). Differences among multiple groups were compared with single factor analysis of variance (ANOVA) while the comparison between two groups was detected with LSD method. A P value $<0.05$ was considered statistically significant.

\section{Results}

Twelve weeks after aortic constriction, 28 rabbits survived and met the criteria of heart failure including 10 in the sham group, 9 in the HF group, and 9 in the CCM group. One rabbit in HF group die of pneumothorax during the surgery. One rabbit in CCM group die of massive haemorrhage due to ascending aorta injuries. The successful rate to build heart failure model was 90\%. After CCM, 100\% survival was observed in all groups.

Effects of CCM treatment on histological changes

As shown in Fig. 1A, photomicrographs of heart tissue sections of H\&E staining in the HF group showed disordered arrangement of myocardial cells, partial myocardial necrosis, 


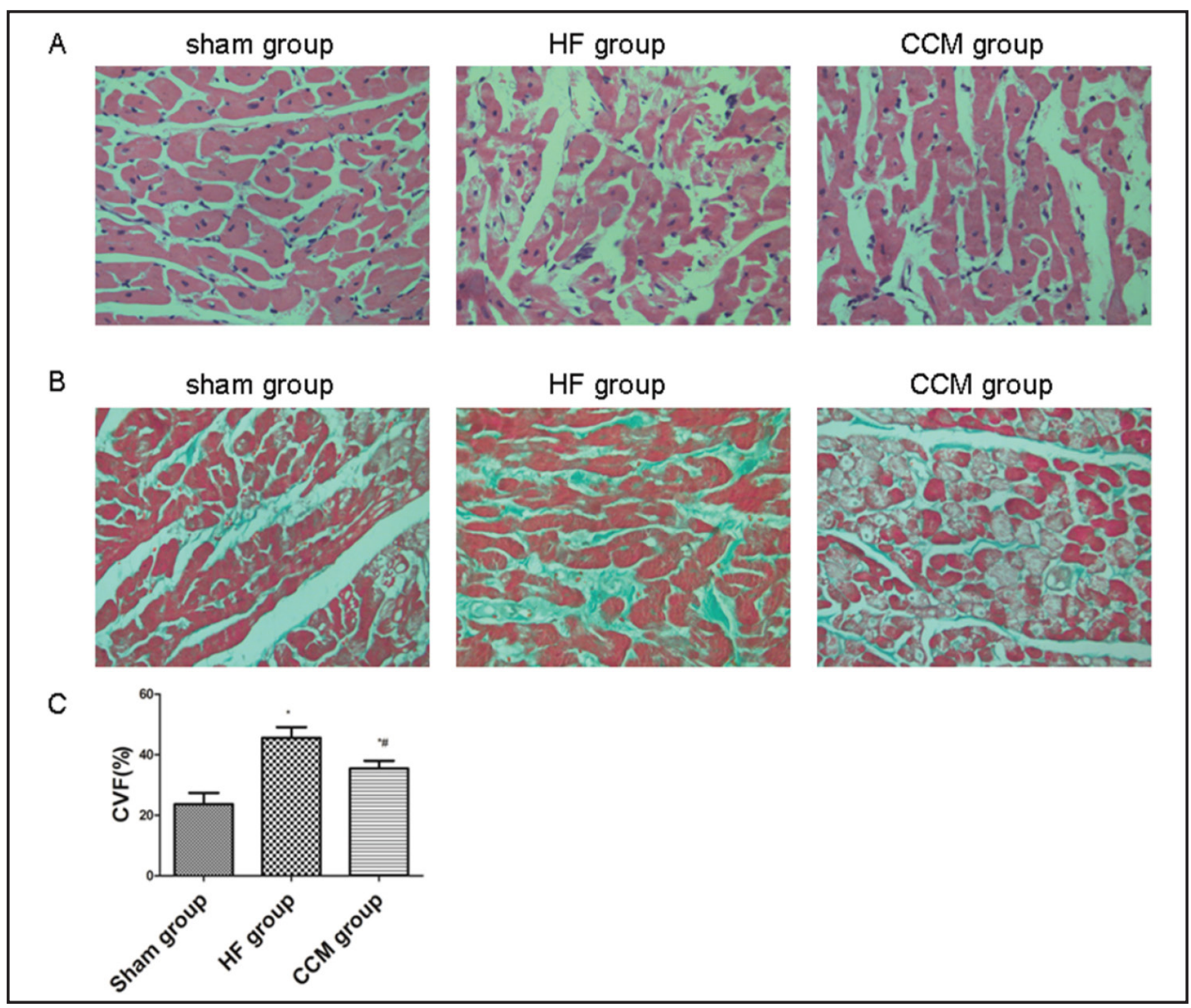

Fig. 1. Effect of CCM treatment on myocardial histological changes. (A) Representative myocardium of each group with H\&E staining. $\times 400$. (B) Representative myocardium of each group with Masson's trichrome staining. $\times 400$. (C) Quantitative analysis of collagen contents $\left({ }^{*} \mathrm{P}<0.05\right.$ vs. sham group; ${ }^{*} \mathrm{P}<0.05$ vs. HF group).

fibrous tissue proliferation and inflammatory cells infiltration, as compared with sham group. Pathological changes were alleviated in CCM group compared with HF group, as demonstrated by the regularly arranged cardiomyocytes and decreased fibrous tissues.

To assess the changes in cardiac interstitial fibrosis, histological sections of the heart were observed morphologically with Masson's trichrome staining and examined by CVF. As shown in Fig. 1B, heart tissue in the HF group presented a massive and intensive collagen accumulation compared with sham group. CVF in the HF group was significantly increased ( $P$ $<0.05$ ). After administration with CCM, areas of fibrotic heart tissue were obviously reduced. CVF in CCM group was remarkably decreased $(\mathrm{P}<0.05)$ (Fig. 1C).

\section{Effect of CCM treatment on cardiac fibroblast differentiation}

$\alpha$-SMA is a surrogate maker for differentiation of fibroblast to myofibroblast. The level of $\alpha$-SMA by immunostaining assay was used as one way to assess the essential role of CCM treatment in differentiation of fibroblast to myofibroblast, as shown in Fig. 2A. Compared with sham group, the percentage of positive areas of $\alpha$-SMA was significantly increased by approximately $15 \%$ in the HF group $(\mathrm{P}<0.05)$. By contrast, CCM treatment markedly reduced the expression of $\alpha$-SMA by approximately $8 \%$, as compared to the HF group (P < 0.05 ) (Fig. 2B). Subsequently, we investigated the effect of CCM on the expression of $\alpha$-SMA

\section{KARGER}




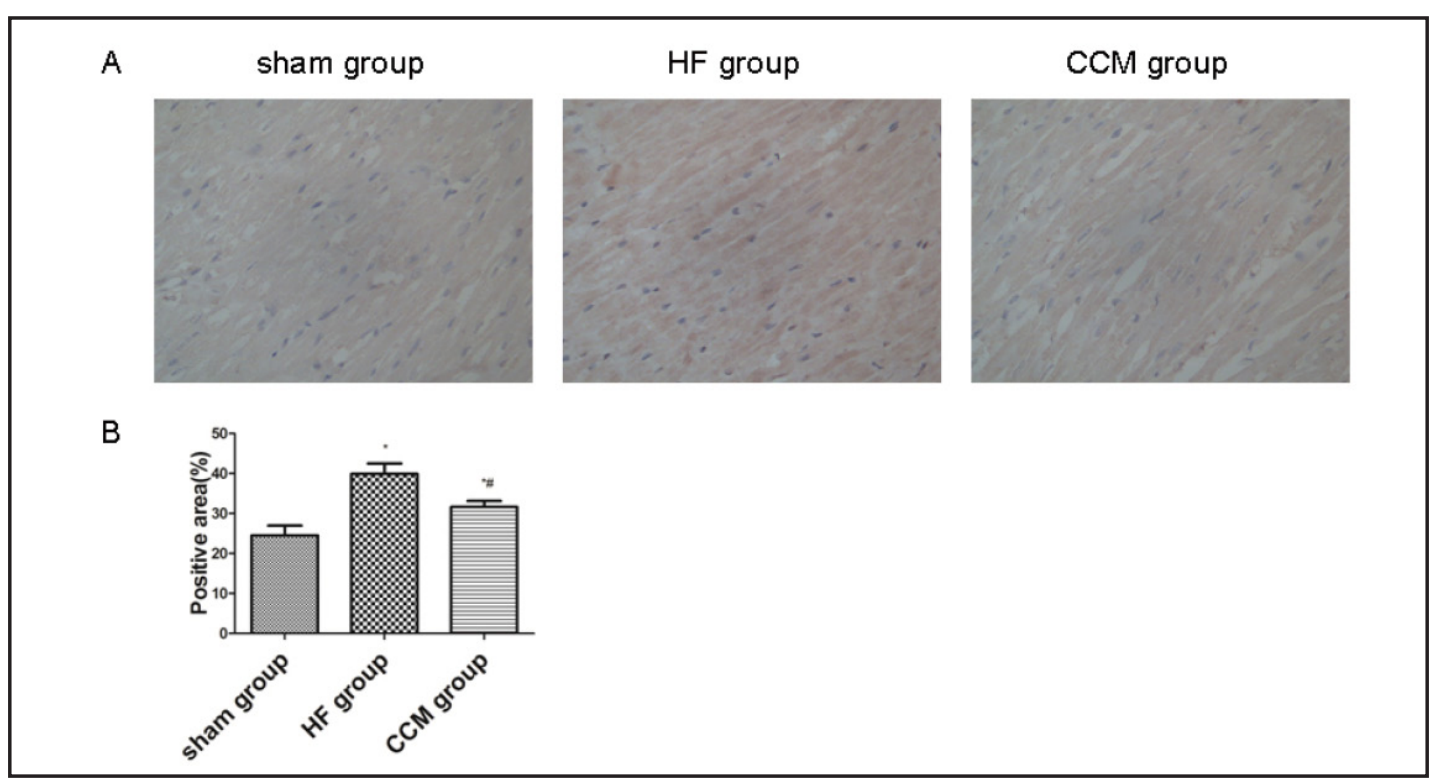

Fig. 2. Effect of CCM treatment on protein expression of $\alpha$-SMA. (A) Immunohistochemical staining of $\alpha$-SMA in each group. (B) Quantitative analysis of the $\alpha$-SMA stained in each group. The columns and error bars represent means $\pm \mathrm{SD}$. ( $\mathrm{P}<0.05$ vs. sham group; \# $\mathrm{P}<0.05$ vs. HF group).

by western blot. Consistent with the immunohistochemistry data, protein levels of $\alpha$-SMA were remarkably increased in HF group compared with sham group. Notably, CCM treatment attenuated these changes (Fig. 3A, G).

Effect of CCM treatment on the expressions of collagen I, collagen III, MMP2, MMP9 and TIMP1

The myocardial extracellular matrix is a complex structure that is mainly formed by interconnecting collagen and fibronectin. The cardiac collagen network consists of five types of collagen: types I, III, IV, V and VI. Collagen I and collagen III account for more than $95 \%$ of the total cardiac collagen [24]. Western blot was used to clarify the effects of CCM on protein expressions of myocardial collagen I and collagen III. The results showed that, compared with the sham group, the protein expressions of collagen I and collagen III increased more significantly in the HF group $(\mathrm{P}<0.05)$. The CCM treatment contributed to markedly reduced protein level of collagen I and collagen III $(\mathrm{P}<0.05)$, as compared with the HF group (Fig. $3 \mathrm{~A}, \mathrm{~B}, \mathrm{C})$.

The MMPs are ECM proteolyses enzymes that are involved in collagen degradation. Tissue matrix metalloproteinase inhibitors (TIMPs) are specific inhibitors of MMPs which can regulate MMP activity in tissues. The predominant forms of MMPs and TIMPs involved in ECM alterations are MMP2, MMP9 and TIMI1. In our study, protein expressions of MMP2, MMP9 and TIMI1 were significantly upregulated in HF group compared with sham group (P $<0.05)$. A significant down regulation was observed after CCM therapy $(\mathrm{P}<0.05)$ (Fig. 3A, D, E, F).

Effect of CCM treatment on TGF- $\beta 1 /$ Smad3 signaling pathway in myocardial fibrosis

TGF- $\beta 1$ has been shown to exert biological effects through Smad-dependent signaling pathway and Smad3 pathway has played an essential role in TGF- $\beta 1$ mediated fibrosis [18]. We demonstrated that protein expressions of TGF- $\beta 1$ and Smad3 were increased significantly in HF group compared with sham group, and were restored after the therapy with CCM (P < 0.05) (Fig. 3A, H, I). 


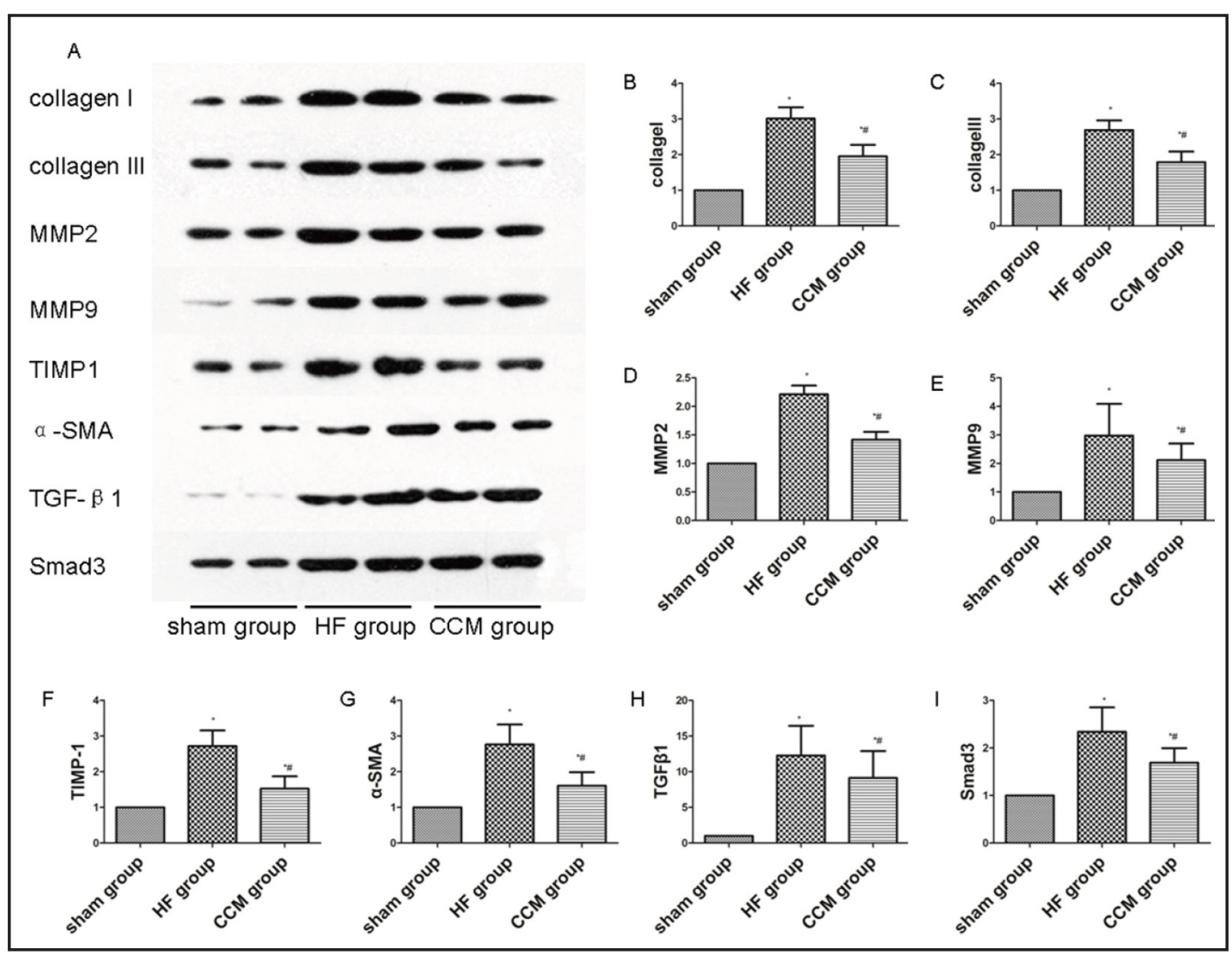

Fig. 3. Effect of CCM treatment on protein expression. (A) Western blot images of collagen I, collagen III, MMP2, MMP9, TIMP1, $\alpha$-SMA, TGF- $\beta 1$ and Smad3. (B) Collagen I expression; (C) Collagen III expression; (D) MMP2 expression; (E) MMP9 expression; (F) TIMP1 expression; (J) $\alpha$-SMA expression; (H) TGF- $\beta 1$ expression; (I) Smad3 expression. The columns and error bars represent means \pm SD. $(* P<0.05$ vs. sham group; \# $\mathrm{P}<0.05$ vs. HF group).

\section{Discussion}

In the present study, we made an effort to understand whether CCM therapy could prevent myocardial fibrosis in heart failure as well as its underlying mechanisms. The major findings of this study include: (1) CCM therapy inhibited cardiac fibrosis in CHF rabbits; (2) CCM therapy attenuated interstitial fibrosis by inhibiting collagen production and fibroblast differentiation; (3) CCM therapy decreased MMP2, MMP9 and TIMP1 expressions; (4) The underlying mechanism might involve suppression of TGF- $31 /$ Smad3 signaling pathway.

CCM has been developed as a treatment for CHF through electrical stimulation during myocardial absolute refractory period to increase myocardial contractility. Experimental and clinical studies have highlighted that CCM reversed the molecular remodeling associated with heart failure [8]. We have previously demonstrated that CCM could normalize the expressions of SERCA2a/phospholamban and miR-133 in CHF rabbits [16], which might contribute to its wide range of cardioprotective action. Previous studies have reported CCM could improve cardiac remodeling by echocardiography and histological assessment and normalizes expressions of key cytoskeletal proteins and matrix metalloproteinase $[13,15]$. In this study, we further investigated the effect of CCM therapy on myocardial fibrosis. Due to the small size of rabbit heart, only one electrode was sutured to left ventricular anterior wall to deliver CCM. In addition, EPS320 Cardiac Stimulator was used in our study to generate CCM signals instead of Optimizer implantable device which was used in clinical studies. 


\section{Cellular Physiology Cell Physiol Biochem 2016;39:294-302 \begin{tabular}{cc|c} 
DOI: 10.1159/000445624 & Ond 2016 The Author(s). Published by S. Karger AG, Basel \\
www.karger.com/cpb
\end{tabular} \\ Zhang et al.: Cardiac Contractility Modulation Attenuate Myocardial Fibrosis}

Myocardial fibrosis is a hallmark of heart disease and plays a vital role in cardiac remodeling during CHF, which is characterized by an increase in collagen synthesis and decrease in collagen degradation in the myocardium, resulting in disproportionate collagen deposition [25]. Myocardial fibrosis has the potential to increase myocardial mass at the expense of cardiac function, leading to a vicious cycle. Previous studies showed CCM reduced the volume fraction of interstitial fibrosis of the myocardium in CHF dog [14]. Likewise, we found that CCM therapy decreased the collagen volume fraction (CVF) in CHF rabbit by Masson's trichrome. In addition, we revealed that CCM inhibited collagen I and collagen III synthesis by western blot method, which played an important part in myocardial fibrosis.

Cardiac fibroblasts are the main source for synthesis of myocardial interstitial collagen. The function of collagen is significantly improved after differentiation to myofibroblast. $\alpha$-SMA is a surrogate maker of myofibroblast. Previous studies indicated the involvement of TGF- $\beta 1$ in the process of fibroblast differentiation [26]. In the present study, we found that CCM therapy attenuated $\alpha$-SMA expression level. In the meantime, protein levels of TGF- $\beta 1$ in CCM group were significantly decreased compared with HF group, suggesting that CCM could alleviate fibroblast proliferation by effectively inhibiting expression of TGF- $\beta 1$.

MMPs are considered to be pivotal factors which influence the deposition of ECM. TIMPs could regulate MMPs activity. The balance between TIMP and MMP exerts an important role in myocardial fibrosis. MMP2 and MMP9 have been proven to play vital roles in cardiac remodeling [27]. Previously basic studies revealed that treatment with CCM decreased MMP1, MMP-2 and MMP-9 mRNA and protein expression, without affecting TIMP expression [15]. Data from our study are in agreement with the previous report that CCM therapy down regulates the expression of MMP2, MMP9 and TIMP1. With administration of CCM, the expression of TGF- $\beta 1$ was declined as well. Accumulating evidence suggests that MMPs activity is regulated by TGF- $\beta 1$ [28]. These findings indicate that CCM inhibits the expression of MMPs potentially via down regulation of TGF- $\beta 1$.

TGF- $\beta 1$ plays a crucial role in cardiac fibrosis. The profibrotic actions of TGF- $\beta 1$ are mediated through induction of its downstream effectors. Smad is a well characterized downstream molecular of TGF- $\beta 1$ signaling [29]. Previous studies have revealed that Smad3 is a key mediator of TGF- $\beta 1$ in the pathogenesis of myocardial fibrosis [30]. As a main downstream signal transducer of TGF- $\beta 1$, Smad3 can be phosphorylated by activated type I receptor of TGF- $\beta 1$ and enter the nucleus to mediate the transcriptions of target genes including collagen I, collagen III, $\alpha$-SMA and MMPs [31]. The present study demonstrated that both mRNA and protein level of TGF- $\beta 1$ and Smad3 were increased notably in HF group and significantly reduced with CCM therapy. Those changes were accompanied by collagen I, collagen III, $\alpha$-SMA, MMP2 and MMP9. These results suggested that CCM therapy could suppress TGF- $\beta 1 /$ Smad3 signaling pathway, which might contribute to its attenuation of myocardial fibrosis in heart failure.

In conclusion, the present study demonstrates that TGF- $\beta 1 /$ Smad3 signaling pathway and downstream collagen I, collagen III, $\alpha$-SMA, MMP2 and MMP9 genes are inhibited by CCM therapy in HF group. CCM therapy has exerted protective effects against myocardial fibrosis in CHF rabbits by inhibiting TGF- $\beta 1 / \mathrm{Smad} 3$ signaling pathway. These results provide experimental evidence for application of CCM in CHF treatment.

\section{Acknowledgments}

This work was supported by Natural Science Foundation of Hebei Province, China (No. H2015307037).

\section{Disclosure Statement}

None.

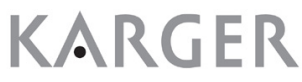




\section{Cellular Physiology Cell Physiol Biochem 2016;39:294-302

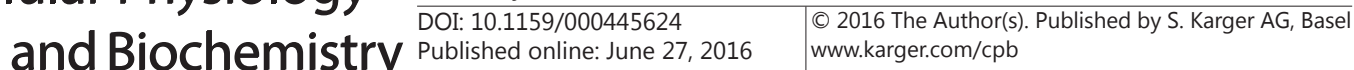 \\ Zhang et al.: Cardiac Contractility Modulation Attenuate Myocardial Fibrosis}

\section{References}

1 Garcia R, Nistal JF, Merino D, Price NL, Fernandez-Hernando C, Beaumont J, Gonzalez A, Hurle MA, Villar AV: p-SMAD2/3 and DICER promote pre-miR-21 processing during pressure overload-associated myocardial remodeling. Biochim Biophys Acta 2015;1852:1520-1530.

2 Shen N, Li X, Zhou T, Bilal MU, Du N, Hu Y, Qin W, Xie Y, Wang H, Wu J, Ju J, Fang Z, Wang L, Zhang Y: Shensong Yangxin Capsule prevents diabetic myocardial fibrosis by inhibiting TGF-beta1/Smad signaling. J Ethnopharmacol 2014;157:161-170.

3 Schelbert EB, Fonarow GC, Bonow RO, Butler J, Gheorghiade M: Therapeutic targets in heart failure: refocusing on the myocardial interstitium. J Am Coll Cardiol 2014;63:2188-2198.

4 Zeglinski MR, Hnatowich M, Jassal DS, Dixon IM: SnoN as a novel negative regulator of TGF-beta/Smad signaling: a target for tailoring organ fibrosis. Am J Physiol Heart Circ Physiol 2015;308:H75-82.

5 Abraham WT, Lindenfeld J, Reddy VY, Hasenfuss G, Kuck KH, Boscardin J, Gibbons R, Burkhoff D: A randomized controlled trial to evaluate the safety and efficacy of cardiac contractility modulation in patients with moderately reduced left ventricular ejection fraction and a narrow QRS duration: study rationale and design. J Card Fail 2015;21:16-23.

6 Borggrefe M, Burkhoff D: Clinical effects of cardiac contractility modulation (CCM) as a treatment for chronic heart failure. Eur J Heart Fail 2012;14:703-712.

7 Kuschyk J, Roeger S, Schneider R, Streitner F, Stach K, Rudic B, Weiss C, Schimpf R, Papavasilliu T, Rousso B, Burkhoff D, Borggrefe M: Efficacy and survival in patients with cardiac contractility modulation: Long-term single center experience in 81 patients. Int J Cardiol 2015;183c:76-81.

8 Lyon AR, Samara MA, Feldman DS: Cardiac contractility modulation therapy in advanced systolic heart failure. Nat Rev Cardiol 2013;10:584-598.

9 Kloppe A, Mijic D, Schiedat F, Bogossian H, Mugge A, Rousso B, Lemke B: A randomized comparison of 5 versus 12 hours per day of cardiac contractility modulation treatment for heart failure patients: A preliminary report. Cardiol J DOI:10.5603/CJ.a2015.0073.

10 Butter C, Rastogi S, Minden HH, Meyhofer J, Burkhoff D, Sabbah HN: Cardiac contractility modulation electrical signals improve myocardial gene expression in patients with heart failure. J Am Coll Cardiol 2008;51:1784-1789.

11 Gupta RC, Mishra S, Wang M, Jiang A, Rastogi S, Rousso B, Mika Y, Sabbah HN: Cardiac contractility modulation electrical signals normalize activity, expression, and phosphorylation of the $\mathrm{Na}+-\mathrm{Ca} 2+$ exchanger in heart failure. J Card Fail 2009;15:48-56.

12 Tschope C, Van Linthout S, Spillmann F, Klein O, Biewener S, Remppis A, Gutterman D, Linke WA, Pieske B, Hamdani N, Roser M: Cardiac contractility modulation signals improve exercise intolerance and maladaptive regulation of cardiac key proteins for systolic and diastolic function in HFpEF. Int J Cardiol 2016;203:1061-1066.

13 Zhang Q, Chan YS, Liang YJ, Fang F, Lam YY, Chan CP, Lee AP, Chan KC, Wu EB, Yu CM: Comparison of left ventricular reverse remodeling induced by cardiac contractility modulation and cardiac resynchronization therapy in heart failure patients with different QRS durations. Int J Cardiol 2013;167:889-893.

14 Imai M, Rastogi S, Gupta RC, Mishra S, Sharov VG, Stanley WC, Mika Y, Rousso B, Burkhoff D, Ben-Haim S, Sabbah HN: Therapy with cardiac contractility modulation electrical signals improves left ventricular function and remodeling in dogs with chronic heart failure. J Am Coll Cardiol 2007;49:2120-2128.

15 Rastogi S, Mishra S, Zaca V, Mika Y, Rousso B, Sabbah HN: Effects of chronic therapy with cardiac contractility modulation electrical signals on cytoskeletal proteins and matrix metalloproteinases in dogs with heart failure. Cardiology 2008;110:230-237.

16 Ning B, Qi X, Li Y, Liu H, Zhang F, Qin C: Biventricular pacing cardiac contractility modulation improves cardiac contractile function via upregulating SERCA2 and miR-133 in a rabbit model of congestive heart failure. Cell Physiol Biochem 2014;33:1389-1399.

17 Khan R: Examining potential therapies targeting myocardial fibrosis through the inhibition of transforming growth factor-beta 1. Cardiology 2007;108:368-380.

18 Biernacka A, Dobaczewski M, Frangogiannis NG: TGF-beta signaling in fibrosis. Growth Factors 2011;29:196-202.

19 Heger J, Schulz R, Euler G: Molecular switches under TGFbeta signalling during progression from cardiac hypertrophy to heart failure. Br J Pharmacol 2016;173:3-14. 


\section{Cellular Physiology Cell Physiol Biochem 2016;39:294-302

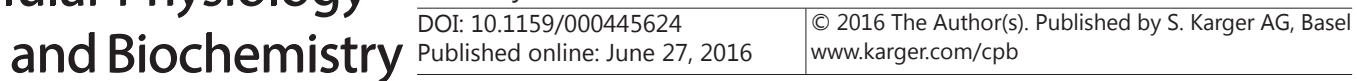 \\ Zhang et al.: Cardiac Contractility Modulation Attenuate Myocardial Fibrosis}

20 Qi HP, Wang Y, Zhang QH, Guo J, Li L, Cao YG, Li SZ, Li XL, Shi MM, Xu W, Li BY, Sun HL: Activation of peroxisome proliferator-activated receptor gamma (PPARgamma) through NF-kappaB/Brg1 and TGFbeta1 pathways attenuates cardiac remodeling in pressure-overloaded rat hearts. Cell Physiol Biochem 2015;35:899-912.

21 Zhang Y, Huang XR, Wei LH, Chung AC, Yu CM, Lan HY: miR-29b as a therapeutic agent for angiotensin IIinduced cardiac fibrosis by targeting TGF-beta/Smad3 signaling. Mol Ther 2014;22:974-985.

22 Matkovich SJ, Wang W, Tu Y, Eschenbacher WH, Dorn LE, Condorelli G, Diwan A, Nerbonne JM, Dorn GW, 2nd: MicroRNA-133a protects against myocardial fibrosis and modulates electrical repolarization without affecting hypertrophy in pressure-overloaded adult hearts. Circ Res 2010;106:166-175.

23 Duisters RF, Tijsen AJ, Schroen B, Leenders JJ, Lentink V, van der Made I, Herias V, van Leeuwen RE, Schellings MW, Barenbrug P, Maessen JG, Heymans S, Pinto YM, Creemers EE: miR-133 and miR-30 regulate connective tissue growth factor: implications for a role of microRNAs in myocardial matrix remodeling. Circ Res 2009;104:170-178,176p following 178.

24 An Z, Yang G, He YQ Dong N, Ge LL, Li SM, Zhang WQ: Atorvastatin reduces myocardial fibrosis in a rat model with post-myocardial infarction heart failure by increasing the matrix metalloproteinase-2/tissue matrix metalloproteinase inhibitor-2 ratio. Chin Med J (Engl) 2013;126:2149-2156.

25 Wang Y, Wu Y, Chen J, Zhao S, Li H: Pirfenidone attenuates cardiac fibrosis in a mouse model of TAC-induced left ventricular remodeling by suppressing NLRP3 inflammasome formation. Cardiology 2013;126:1-11.

26 Hutcheson JD, Ryzhova LM, Setola V, Merryman WD: 5-HT(2B) antagonism arrests non-canonical TGFbeta1-induced valvular myofibroblast differentiation. J Mol Cell Cardiol 2012;53:707-714.

27 Cogni AL, Farah E, Minicucci MF, Azevedo PS, Okoshi K, Matsubara BB, Zanati S, Haggeman R, Paiva SA, Zornoff LA: Metalloproteinases- 2 and -9 predict left ventricular remodeling after myocardial infarction. Arq Bras Cardiol 2013;100:315-321.

28 Khan R, Sheppard R: Fibrosis in heart disease: understanding the role of transforming growth factor-beta in cardiomyopathy, valvular disease and arrhythmia. Immunology 2006;118:10-24.

29 Pardali E, Ten Dijke P: TGFbeta signaling and cardiovascular diseases. Int J Biol Sci 2012;8:195-213.

30 Divakaran V, Adrogue J, Ishiyama M, Entman ML, Haudek S, Sivasubramanian N, Mann DL: Adaptive and maladptive effects of SMAD3 signaling in the adult heart after hemodynamic pressure overloading. Circ Heart Fail 2009;2:633-642.

31 Zhu JN, Chen R, Fu YH, Lin QX, Huang S, Guo LL, Zhang MZ, Deng CY, Zou X, Zhong SL, Yang M, Zhuang J, Yu XY, Shan ZX: Smad3 inactivation and MiR-29b upregulation mediate the effect of carvedilol on attenuating the acute myocardium infarction-induced myocardial fibrosis in rat. PLoS One 2013;8:e75557. 